
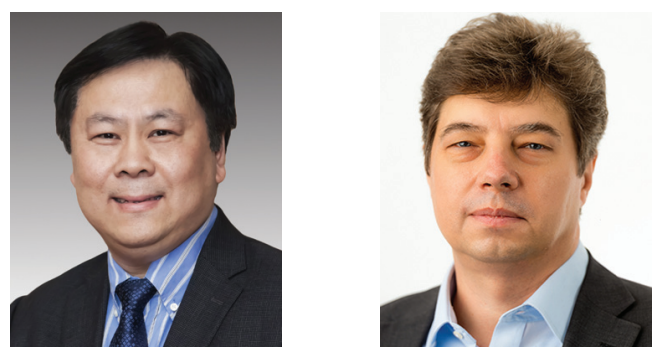

\title{
Advanced Photonics: keeping up with the community
}

It was a very challenging year for all of us and we appreciate very much the continuing support and commitment of our readers and authors. Advanced Photonics enters its third year. We encourage you to check out volume 2 of the journal. It has many exciting articles to read and learn from. Despite of all the challenges researchers experienced during lockdowns and research laboratories shutdowns, the number of submitted manuscripts increased a bit shy of $100 \%$. The number of published papers increased by more than $30 \%$ compared to volume 1 . The published articles were read approximately 300,000 times (on average more than 3,000 downloads per article), an amazing achievement which reflects hard work of our authors.

In 2020, we welcomed two new Editorial Board members, Professor Síle Nic Chormaic and Professor Jia Zhu, who will cover areas where we have an increased rate of submissions. We are extremely grateful to Professor Kishan Dholakia, who moved on to new challenges after serving on the Editorial Board since the journal's inception.

We had several new initiatives in 2020. The best paper prize for volume 1 was awarded in April to Professor Yuri Kivshar from Australian National University, based on the rate of citations during the year of publication. We published the theme issue devoted to the 60th anniversary of a laser, which had a very good response from readers. In order to stay close to the optics research community in these challenging times, we organized the Advanced Photonics Colloquium in January 2021, attended online by more than 500 participants. Our authors presented their latest research and our readers had a chance to ask questions. Lively discussions meant that every session overran its scheduled time. The recording of the Colloquium is now available.

We hope very much that in 2021 we will have a chance to meet with our readers and authors in person. We always welcome your suggestions on any aspect of the journal development-just drop us a line and we will discuss it with you.
Xiao-Cong (Larry) Yuan Co-Editor-in-Chief

Anatoly Zayats Co-Editor-in-Chief 